\title{
UTILIZANDO KHAN ACADEMY EM UMA ESCOLA BRASILEIRA
}

\section{${ }^{1}$ Anandy Kassis de Faria Alvim Hannas, ${ }^{2}$ Fernando Jerri de Oliveira, ${ }^{3}$ Izadora Cristina Corrêa Silva, ${ }^{4}$ José Carlos de Souza, ${ }^{5}$ Lidiane Hott de Fúcio Borges, ${ }^{6}$ Thales Reis Hannas}

${ }^{1}$ Professora da Faculdade de Ciências Gerenciais de Manhuaçu - MG (FACIG). Graduada em Desenho Industrial pela Universidade do Estado de Minas Gerais e Administração pela Pontifícia Universidade Católica de Minas Gerais. Especialização em Informática na Educação e em Ecoturismo pela UFLA. Mestrado em Administração com ênfase em Marketing pela PUC-MG em parceria com a Fundação Dom Cabral.

${ }^{2}$ Professor de Matemática do Colégio América em Manhuaçu - MG. Professor de Ciências Físicas e Biológicas da Secretaria De Estado Da Educação. Graduado em Ciências Físicas e Biológicas pela Faculdade de Filosofia, Ciências e Letras de Carangola e em Matemática pela Faculdade de Filosofia, Ciências e Letras de Carangola. Especialização em Matemática pela Universidade Federal de São João Del-Rei. Especialização em Educação Ambiental pelas Faculdades Integradas de Jacarepaguá.

${ }^{3}$ Professora e Coordenadora do Curso de Arquitetura da Faculdade de Ciências Gerenciais de Manhuaçu - MG (FACIG). Graduada em Arquitetura e Urbanismo pela Universidade Federal de Viçosa - MG (UFV). Mestre em Engenharia Civil pela Universidade Federal de Viçosa-MG (UFV).

${ }^{4}$ Professor e Coordenador do Curso de Administração da Faculdade de Ciências Gerenciais de Manhuaçu - MG (FACIG). Graduado em Ciências Militares (CFO - Curso de Formação de Oficiais) pela Academia da Polícia Militar de Minas Gerais e em Administração pela Faculdade de Ciências Administrativas de Caratinga. Bacharel em Direito pela Universidade Cruzeiro do Sul - SP. Especialista em Gestão e Tecnologia da Qualidade pela Fundação CEFETMINAS e em Ciências Jurídicas pela Universidade Cruzeiro do Sul - SP. Mestre em Administração pela Faculdades Integradas de Pedro Leopoldo.

${ }^{5}$ Professora e Coordenadora do Curso de Licenciatura em Matemática da Faculdade de Ciências Gerenciais de Manhuaçu - MG (FACIG). Graduada em Matemática pela Faculdade de Filosofia, Ciências e Letras Santa Marcelina de Muriaé - MG (FAFISM). Pós Graduada em Matemática e Estatística pela Universidade Federal de Lavras - MG (UFLA). Mestre em Engenharia e Ciências dos Materiais pela Universidade Estadual Norte Fluminense - RJ (UENF).

${ }^{6}$ Diretor da Faculdade de Ciências Gerenciais de Manhuaçu - MG (FACIG). Mestre em Administração pela PUC MG. Pós-graduado em Análise de Sistemas pela UNA / BH. Pósgraduado em Informática na Educação pela UFLA. Pós-graduado em Formação em Educação a Distância pela UNIP. Graduado em Engenharia Civil pela Universidade Federal de Minas Gerais. Graduado em Gestão de Tecnologia pela UNIP.

Resumo: Este trabalho apresenta os resultados da utilização da plataforma virtual de aprendizagem Khan Academy pelos alunos de uma escola privada do ensino fundamental e médio, em uma tentativa de verificar se a mesma pode ser utilizada tanto para dirimir dúvidas, quanto para obter uma maior motivação dos alunos no estudo de matemática.

Palavras-chave: ambiente virtual de aprendizagem, matemática, Khan Academy 
Abstract: this work reports the results obtained in a Brazilian private school by adopting Khan Academy plataform as support for math discipline in order to verify if it can be used to solve doubts and to motivate the students in the mathematics subject

Keywords: virtual learning enviroment, mathematics, Khan Academy

\section{INTRODUÇÃO}

Valendo-se da tríade "ler, escrever e contar", a Matemática ocupa o lugar das disciplinas que mais reprova o aluno na escola. A justificativa que a comunidade escolar dá a esta "incapacidade" do aluno com esta área do conhecimento é que "matemática é difícil" e o senso comum confere-lhe o aval. Como matemática é considerada útil, o aluno não pode passar para a série seguinte sem atestar seu conhecimento na disciplina e desta forma se aceita inclusive que o aluno seja reprovado apenas em matemática, nem que seja por décimos para atingir a média instituída pela escola onde estuda. (SILVEIRA, 2002).

Com o intuito de "remar contra a corrente" e desconstruir esta crendice popular de que "matemática é difícil", o Colégio América, instituição privada, sediada na cidade de Manhuaçu, no Estado de Minas Gerais, organizou reuniões e discussões com os professores da disciplina de matemática visando a encontrar meios para motivar os alunos no estudo da relevante disciplina.

Como hoje a tecnologia é muito presente na vida dos jovens, que possuem não só atração, mas grande destreza com a mesma, sugeriu-se a adoção de aplicativos que pudessem trabalhar com a disciplina como fator motivador para que os estudantes pudessem se envolver mais ativamente nas atividades acadêmicas.

Outro aspecto destacado nas discussões foi a escolha de algo que proporcionasse atividades desafiadoras, para, assim, tornar o estudo uma fonte de satisfação que prendesse a atenção dos alunos.

$$
\begin{gathered}
\text { Após a análise de vários } \\
\text { aplicativos e sites de plataformas }
\end{gathered}
$$

educacionais, hospedadas na internet, optou-se pela adoção do ambiente virtual de aprendizagem, fundada pelo indiano Salman Khan, Khan Academy que é hoje referência mundial em cursos abertos online de massa.

Khan Academy define-se como uma organização sem fins lucrativos que possui como objetivo alterar para melhor a educação, por meio da disponibilização gratuita de conteúdo educacional de qualidade pela internet.

Fundada em 2006, a Khan Academy possui cerca de seis milhões de usuários mensais, de várias partes do mundo. Estão disponíveis mais de 4.500 aulas em vídeos, abrangendo matemática, ciências, economia, humanidades e programação de computadores. A seção de matemática cobre desde aritmética até álgebra linear.

Desde que a Khan Academy foi instituída, seus vídeos foram vistos por mais de 365 milhões de pessoas, e cerca de 2 milhões de problemas foram resolvidos por usuários de todo o mundo. No Brasil, são mais de 300 mil exercícios disponíveis em língua portuguesa.

A maior parte do ambiente educacional envolve um vídeo explicativo sobre determinado assunto, com posteriores questões avaliativas de múltipla escolha.

Há, também, no ambiente Klan, uma parte cujo funcionamento é típico de uma comunidade, na qual o professor pode definir salas de aulas para participação dos alunos em tópicos específicos, com acompanhamento e suporte. Funcionando como uma biblioteca interativa, a plataforma oferece um conjunto de problemas que são gerados automaticamente, baseados no 
nível de proficiência dos estudantes e no desempenho dos mesmos nos exercícios anteriores. São gerados relatórios sobre o desempenho, disponíveis tanto para os alunos quanto para os professores, além de uma modalidade de jogos, cujo objetivo é incentivar a participação dos estudantes. Esta modalidade de jogos foi aperfeiçoada em 2010, com a introdução de medalhas e pontos no ambiente virtual, tornando-o típico de jogos - gamification - palavra que está "na moda" e que significa agregar elementos comuns aos jogos ao ambiente educacional.

Esse termo foi introduzido pela primeira vez, no ano de 2002, por Nick Pelling, um programador de computador britânico criador de diversos jogos na década de 80 e se refere ao uso de técnicas de jogos as quais visam a enriquecer conteúdos não relacionados a jogos, ou seja, visa a obter vantagem devido à predisposição humana de se engajar nos jogos. No contexto educacional, possui como propósito engajar os estudantes no conteúdo, motivando-os pelo ambiente de desafios e recompensas dos jogos. Parte-se do princípio de que é naturalmente elevado o desejo de competir e de obter prêmios. Além disso, satisfaz a necessidade pessoal de cumprimento de metas obtidas com a conclusão das tarefas.
Como é um tema recente, há pouca literatura a respeito, sendo necessário um maior aprofundamento atestando se há realmente maior motivação por parte dos estudantes e, ainda mais importante, se há benefício acadêmico com a maior retenção do conhecimento, comprovado com 0 aumento das médias escolares.

Este artigo, portanto, justifica-se por buscar analisar os resultados obtidos, comparando as notas médias entre turmas que utilizaram a plataforma da Khan Academy a turmas com aulas ministradas apenas na metodologia expositiva tradicional.

\section{DESENVOLVIMENTO:}

Em 2014, o Colégio América adotou a plataforma Khan Academy como suporte ao ensino da disciplina de matemática para os alunos do ensino fundamental (do sexto ao nono ano) e para os alunos do ensino médio (do primeiro ao terceiro ano).

Objetivando incentivar os estudantes a participar efetivamente do projeto, foram criadas escalas de pontuação que convertem os pontos obtidos no ambiente virtual em pontos reais - nota - para a disciplina de matemática. A escala foi elaborada conforme os quadros abaixo:

Quadro 1 - Escala de pontuação dos alunos do ensino fundamental II

\begin{tabular}{|l|l|}
\hline \multicolumn{2}{|c|}{$\mathbf{6}^{\circ}$ e $7^{\circ}$ anos do ensino fundamental } \\
\hline PONTUAÇÃO NO AMBIENTE VIRTUAL & \multicolumn{1}{|c|}{ PONTOS NA DISCIPLINA } \\
\hline De 1.000 a 10.000 & 0,5 \\
\hline De 10.001 a 20.000 & 1,0 \\
\hline De 20.001 a 30.000 & 1,5 \\
\hline Acima de 30.001 & 2,0 \\
\hline \multicolumn{2}{|c|}{ 8 $^{\circ}$ 9 9 anos do ensino fundamental } \\
\hline PONTUAÇÃO NO AMBIENTE VIRTUAL & \multicolumn{2}{c|}{ PONTOS NA DISCIPLINA } \\
\hline De 1.000 a 35.000 & 0,5 \\
\hline De 35.001 a 70.000 & 1,0 \\
\hline De 70.001 a 105.000 & 1,5 \\
\hline Acima de 105.001 & 2,0 \\
\hline
\end{tabular}


Quadro 2 - Escala de pontuação dos alunos do ensino médio

\begin{tabular}{|l|l|}
\hline \multicolumn{2}{|c|}{ Ensino médio } \\
\hline PONTUAÇÃO NO AMBIENTE VIRTUAL & \multicolumn{2}{|c|}{ PONTOS NA DISCIPLINA } \\
\hline De 1.000 a 10.000 & 0,5 \\
\hline De 10.001 a 20.000 & 1,0 \\
\hline De 20.001 a 30.000 & 1,5 \\
\hline Acima de 30.001 & 2,0 \\
\hline
\end{tabular}

Todos os alunos das turmas avaliadas foram incluídos nas salas de aulas virtuais específicas criadas pelo professor da disciplina, cujo conteúdo se refere ao mesmo do material didático ministrado em cada uma das séries.

Com diversos indicadores disponíveis, foi possível verificar o tempo gasto por cada aluno nas atividades virtuais, a quantidade de conteúdos cujo teor foi - nos termos do ambiente virtual dominado pelos alunos, o número de atividades nas quais cada aluno apresentou dificuldade, o número de medalhas conquistadas, o número de pontos obtido, entre outros.

$\mathrm{Na}$ análise dos resultados obtidos, foram analisados três aspectos. Primeiramente, o tempo médio gasto por cada turma nas atividades. Posteriormente avaliou-se a média dos pontos obtidos por cada uma das turmas. Por fim, realizou-se a comparação com a média escolar obtida no respectivo bimestre do ano de 2013 em relação ao mesmo bimestre do ano de 2014, quando houve a utilização das aulas virtuais do ambiente da Khan Academy.

O gráfico 01 mostra o tempo médio e pontos obtidos pelas turmas nas atividades realizadas no ambiente educacional da Khan Academy.

Os resultados demonstram maior participação dos alunos mais novos, dos anos iniciais do Ensino Fundamental II, os alunos do 6ำ ano, por exemplo, obtiveram 18.604 pontos em 162,83 minutos, e os alunos da $3^{\text {a }}$ série do Ensino Médio alcançaram 8.263 pontos em 35,18 minutos.

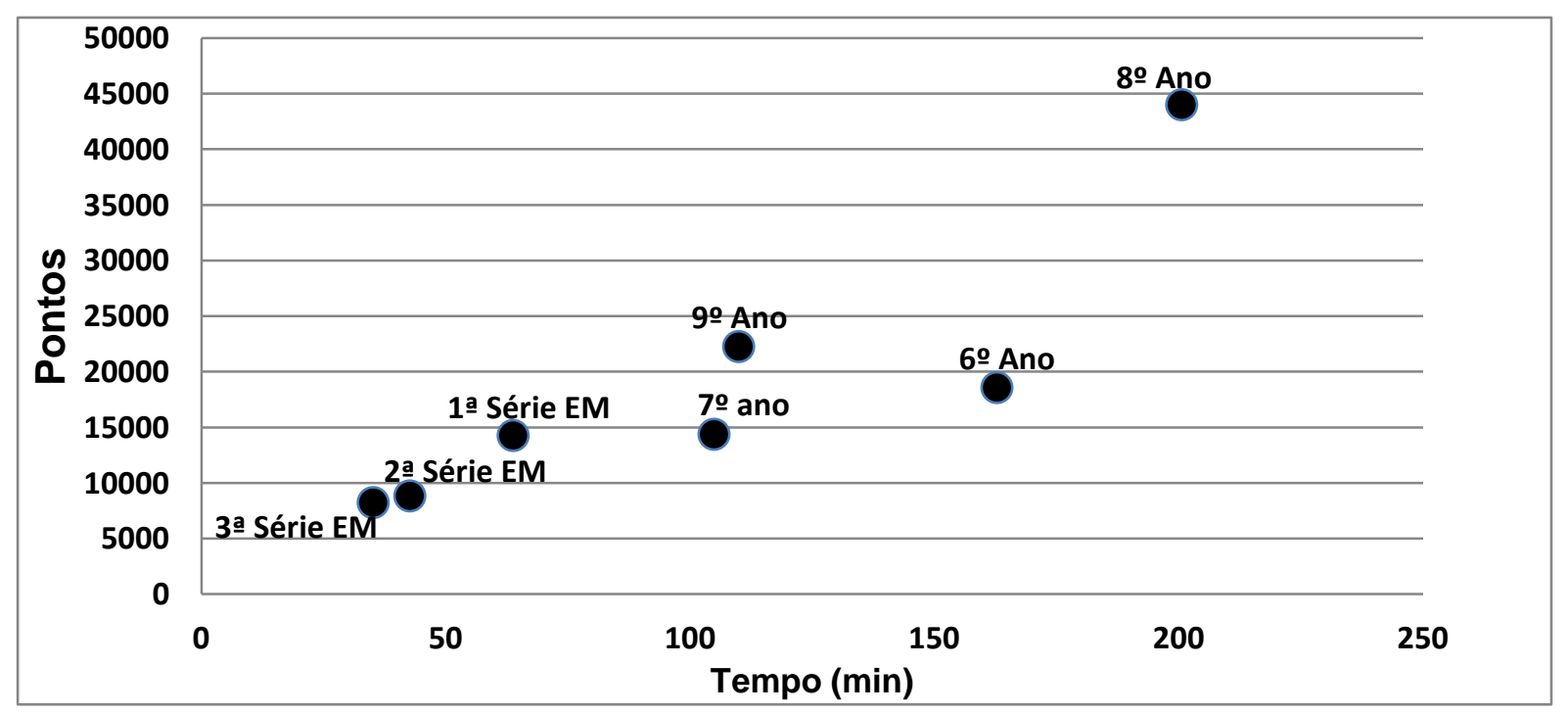

Gráfico 01 - Tempo médio e pontos obtidos pelas turmas nas atividades do ambiente da Khan Academy 
O gráfico 02 apresenta uma comparação das médias escolares obtidas no respectivo bimestre do ano de $2013 \mathrm{em}$ relação ao mesmo bimestre do ano de 2014, quando houve a utilização das aulas virtuais do ambiente da Khan Academy.

Têm-se maiores médias escolares, durante o bimestre analisado do ano de 2014, em todo Ensino Fundamental II e Ensino Médio da Educação Básica. Esses resultados demonstram o quanto o uso do ambiente educacional Khan Academy facilitou 0 processo de fixação da aprendizagem da Matemática, refletindo no aumento das médias escolares.

Os dados revelam também, maiores médias escolares dos alunos do Ensino Fundamental II, demonstrando, mais uma vez, uma maior aceitação e interesse por parte dos alunos mais novos em trabalhar com aulas envolvendo a tecnologia.

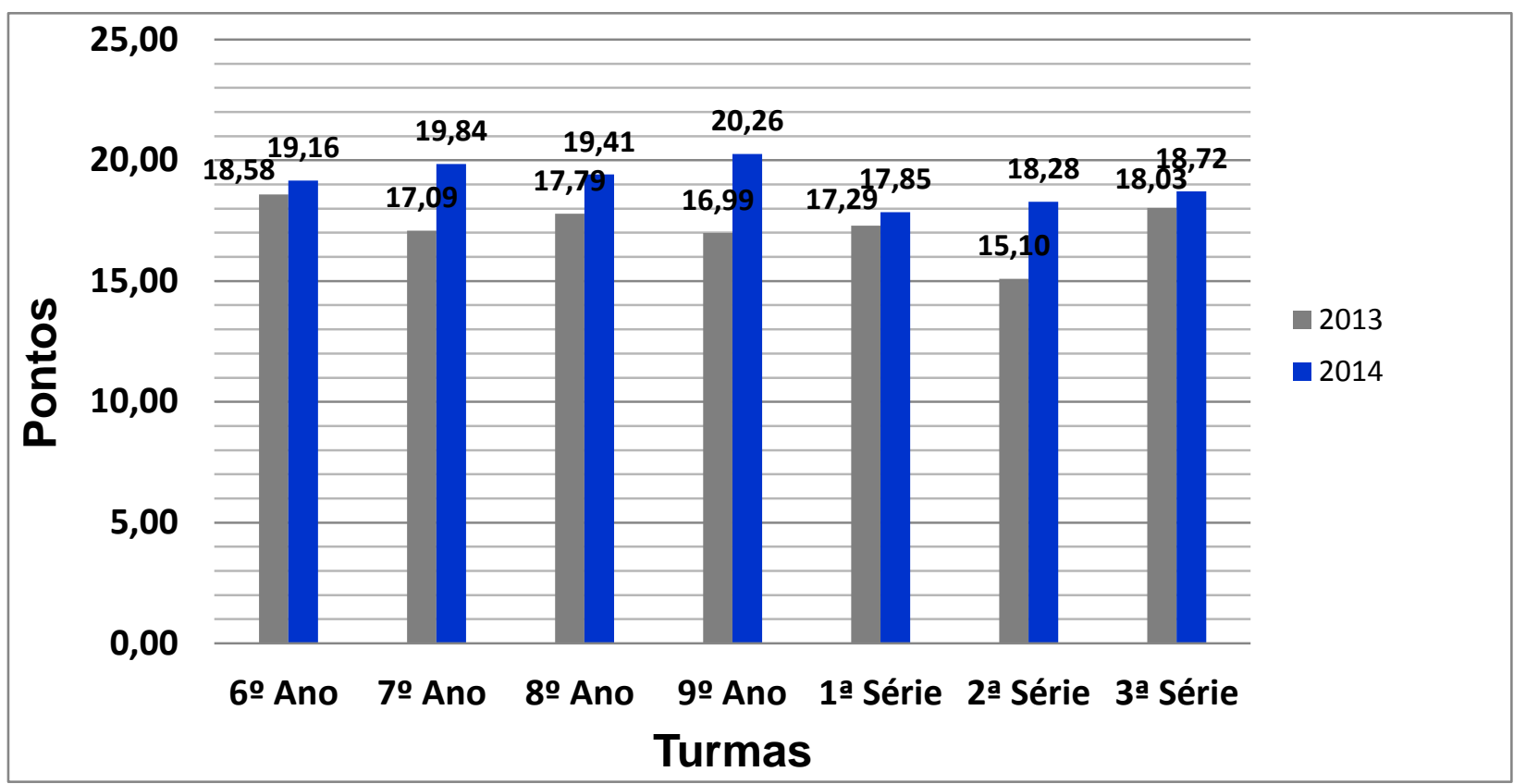

\section{Gráfico 02 - Média escolar obtida no respectivo bimestre do ano de 2013 em relação ao mesmo bimestre do ano de 2014}

\section{CONSIDERAÇÕES FINAIS:}

Evitou-se adaptar o termo para o português utilizando-se "gamificação", anglicismo que vem sendo adotado também no Brasil. O radical "gam" em português se refere a par, casal e não a jogos.

Neste trabalho, avaliou-se a influência da utilização da técnica de gamification no desempenho dos alunos do ensino fundamental e médio de uma escola privada, Colégio América, sediado na cidade de Manhuaçu, MG, na disciplina de matemática.
Como a cada ano há a progressão dos estudantes para as séries seguintes, salvo alguma reprovação, a comparação não envolveu os mesmos alunos de cada série, mas os resultados demonstram que - uso ambiente educacional Khan Academy, para o processo de ensino aprendizagem da matemática, é eficaz e motivador. Sua similaridade com um jogo o torna mais atrativo e leva o aluno a construir seu próprio conhecimento ao cumprir suas metas para obter pontos.

\section{REFERÊNCIAS BIBLIOGRÁFICAS:}

Gamification. Recuperado: 14 ago 2014. Disponível:http://www.nanodome.com/con undra.co.uk/ 
Khan Academy. Recuperado: 05 ago $2014 . \quad$ Disponível: https://www.khanacademy.org/about

RANGEL, M. Métodos de ensino para a aprendizagem e a dinamização das aulas. 3.ed. São Paulo: Papirus, 2007.

ROSSO, A.J., TAGLIEBER, J. B. Métodos ativos $e$ atividades de ensino. Perspectiva 17, 1992, pg. 37-46

Silveira, M. R. A (2002). Matemática é Difícil. Em Reunião Anual da Associação Nacional de Pesquisa e Pós-Graduação em Educação. Caxambu. Anais. Caxambu: Anped. Recuperado: 24 out. $2008 . \quad$ Disponível: $<$ www.anped.org.br/25/marisarosaniabreu silveirat19.rtf> 